\title{
Designing an Integrated Teaching and Learning of Mathematics and Image Processing in Engineering Technology
}

\author{
Norhayati Bakri", Tuan Salwani Salleh", Zalhan Mohd Zin ${ }^{\#}$ \\ \# Mathematics Section, UniKL Malaysia France Institute, Selangor, 43650, Malaysia \\ E-mail: norhayatibakri@unikl.edu.my; tuansalwani@unikl.edu.my
}

* Industrial Automation Section, UniKL Malaysia France Institute, , Selangor, 43650, Malaysia

E-mail: zalhan@unikl.edu.my

\begin{abstract}
Engineering technology subjects require some mathematical applications as the foundation to succeed in the subjects. However, students find the theoretical subjects like mathematics as unattractive and difficult. This happens due to the inability of engineering technology students to link between mathematical knowledge and technological applications. Furthermore, students are unable to understand the importance of mathematics in engineering technology subjects which consequently contribute to their poor academic performance. The current teaching approach which separates the teaching of mathematics from engineering technology subjects does not encourage students' understanding in both subjects. In this paper, the focus has been given to the development of an integrated teaching and learning module of mathematics and image processing subjects known as Maths-IP Room. It has the purpose to increase students' understanding in both subjects. This proposed module will be designed using ADDIE model. Web-based application and M-learning system will be used as the platforms for the proposed module. This module is hoped to make the acquisition of knowledge in mathematics and image processing can be enhanced.
\end{abstract}

Keywords - Mathematics; Image processing; Instructional design; Teaching and Learning

\section{INTRODUCTION}

In the first year of engineering technology programs, the students are offered basic courses in order to provide them the sufficient skills to further their undergraduate studies. Among the basic courses offered are mathematics, physics, and programming. However, in most cases, many students find that these theoretical subjects are unattractive, difficult and useless. With the expectation of focusing directly on their chosen area of study such as electrical, robotics or mechatronics engineering, the students are disappointed to find out that their first year subjects are similar to their previous studies in secondary school. They perceive that fundamental subjects including mathematics or physics have been given more attention than their engineering or technical subjects. This usually de-motivates the students and decreases their study interest. Furthermore, most students have difficulties to relate the needs of these basic subjects to their engineering subjects.

The importance of motivation and stimulation of interest have often been recognized in the literature [1]-[4]. In [2], the authors believed that poor motivation in studying mathematics is one of the key reasons for the students' incomplete skills. They do not see the real use for the mathematical theory that they have learned. In their study, they found that students failed to acquire sufficient mathematics skills for them to further progress in mathematics-oriented engineering topics such as digital image processing. Even after their first year of study or sometimes after their second year they did not manage to grasp the required mathematical skills. Together with poor motivation and lack of interest in the topic, majority of the students are just taking mathematics subjects with minimum effort and therefore obtain only minimum grades or most of the time they failed the subjects. Similarly, in this study, students were facing the same problems.

As mentioned in [5], a suitable syllabus is one of the most important strategy for an effective learning. This could help the students to increase their motivation, thus improve their skills in the study. The teaching and learning of the subjects especially mathematics could become more interesting by relating directly to the engineering or technical subjects. In the university involved in this study, one of the subjects that require substantial amount of mathematics is image processing (IP). This subject can be considered as one of the main components of computer vision system that has usually been applied in robotics, manufacturing and intelligent 
systems. A comprehensive review was done in [6]. Computer vision has grown from a research area to a widely accepted technology that is capable of providing a significant increase in productivity and improving living standards. It is becoming a mainstream subject of study in computer science and engineering. The authors in [6] have also indicated that the students in computer science and engineering fields should receive some basic education related to computation with images. This is crucial for them to catch up with the rapid explosion of multimedia and the extensive use of video and image-based communications over the internet. So, to increase students' motivation and ability in mathematics for image processing or other engineering subjects in general become one of the huge challenges that the lecturers and universities need to tackle.

In fact, there were some works and studies that have been done to integrate mathematics with image processing or signal processing subjects. In [7], the concepts from digital signal processing have been incorporated into the high school classroom through specialized engineering education. The authors have introduced the Infinity Project, which is a joint effort corporation between university educators, industrial partners, and civic leaders to introduce a signalprocessing-based engineering curriculum at the high school educational level. Meanwhile, in [8], it was mentioned in this paper, in Australia, some tertiary courses are reducing formal mathematics from their computer science courses completely. This situation is also happening in this university. By doing this, the teaching of image processing to students of computer science must use as little mathematics as possible. Therefore, the authors have discussed and introduced methods based on colour image processing to the undergraduate subjects taught at Victoria University of Technology (VUT). Another works that incorporated mathematics and engineering subject was done in [9] where the authors have reviewed and used MATLAB ${ }^{\circledR}$ and Mathcad ${ }^{\circledR}$ for teaching and research in the syllabus of traditional introductory and advanced bio-signal processing subject. All these works had the purpose to increase the student's interest in learning mathematics and engineering subjects.

Like in other higher educational institutions that offer engineering and technical studies for undergraduate, the problems of students' lack of motivation, loss of interest and inability to relate mathematics and engineering subjects become common problems that need to be tackled in this institution. Beside the problems that were mentioned previously which centred more on the students, the other aspect of the problem that was observed could also come from the lecturers themselves. It is usually very difficult for the lecturers from both sections mathematics and engineering to sit together and discuss on these matters. This might due to the fact that engineering or technical lecturers usually assume that all basic mathematical knowledge and skills should have been handled by mathematics lecturers and they do not need to worry about it. On the other hand, mathematics lecturers only deliver mathematics lessons based on its syllabus or curriculum without knowing what, where, how, why or when the topics could be useful for the students to apply in their engineering or technical subjects. This is a typical problem between mathematics and engineering lecturers which do not give any benefits to the improvement in the teaching and learning of both subjects.

The problems and issues that have been described have motivated this research with the aim to improve the ability, increase the motivation and provide adequate skills to the students in learning mathematics and image processing subjects. There are several tasks that will be involved, including (i) the discussion between mathematics and engineering lecturers to identify and map the topics in both subjects, (ii) the integration of mathematics within image processing topics and finally, (3) the case study on the students that will use this method and compare it with the conventional method of teaching and learning for both subjects.

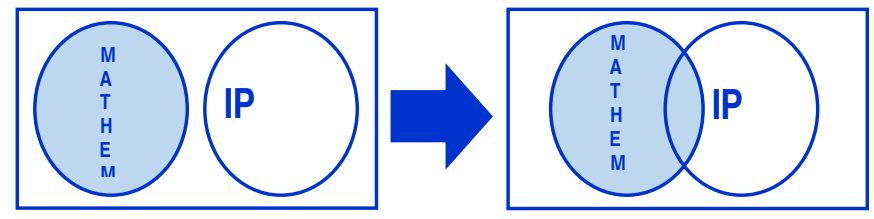

Fig. 1 Left Venn diagram represents the existing approach of teaching mathematics and image processing which is usually performed separately. In right Venn diagram, the intersection area represent several topics in these two subjects that could be integrated.

In this paper, the focus is given to produce a conceptual study on the potential integration of mathematics in image processing subject in our institution. As shown in Figure 1, the related topics in these subjects were identified and later integrated. This involved the comparison and study of various topics in mathematics and image processing and how the integration of these two subjects could be done. It is an important step in order to design an alternative teaching approach by incorporating these two subjects.

\section{METHOD}

All paragraphs must be indented. All paragraphs must be justified, i.e. both left-justified and right-justified.

\section{A. Addie Model}

The ADDIE model is used in the process of designing, developing and implementing a new strategy. ADDIE is the acronym for Analyse, Design, Develop, Implement and Evaluate [10]. This paper describes the process completed in the first phase of the ADDIE model. This phase includes the step to analyse the needs for an instructional improvement. One of the factors considered is to identify the critical issues which need immediate attention in order to ensure students enrolled at the university graduate on time. The issues identified are the poor performance in mathematics and the inability to relate mathematics to image processing. One of the contributing factors that lead to the poor performance in both subjects is the inconsistencies of definitions for common terminologies.

\section{B. Analysis Phase}

In the Analyse Phase, students' performance in mathematics and image processing subjects were investigated. The subjects are FKB10103 (Engineering Technology Mathematics 1), FKB20203 (Engineering Technology Mathematics 2) and FSB33503 (Image 
Processing). They are offered in semester 2,3 and 5 respectively. FKB10103 and FKB20203 are offered by the Mathematics Section while FSB33503 is offered by the Industrial Automation Section. They are among the core subjects in Bachelor of Engineering Technology (Honors) in Industrial Automation and Robotics Technology program in this university. Both FKB10103 and FKB20203 have the purpose to provide adequate and necessary mathematical skills to students. FKB10103 consist of Linear Algebra, Polynomials and Vectors while FKB20203 covers PreCalculus, Calculus and Differential Equations. On the other hand, Image Processing has the purpose to introduce image processing techniques and technology with its topics covering digital image fundamental, image representation, transformation, enhancement, restoration, segmentation and compression.

\section{RESULTS AND DISCUSSION}

\section{A. Students' Performance in Mathematics and Image Processing}

Figure 2 shows that the failure rates in FKB10103 of two different intakes (January 2011 and July 2011) had increased. The failure rate was $5.56 \%$ in January 2011. This rate had drastically increased to $38.89 \%$ in the following semester. This scenario suggests the difficulties faced by the students in comprehending FKB10103. Some students managed to score grade $\mathrm{B}+$ and above in this subject. However, there was a decreased from $22.23 \%$ in January 2011 to $8.34 \%$ in July 2011.

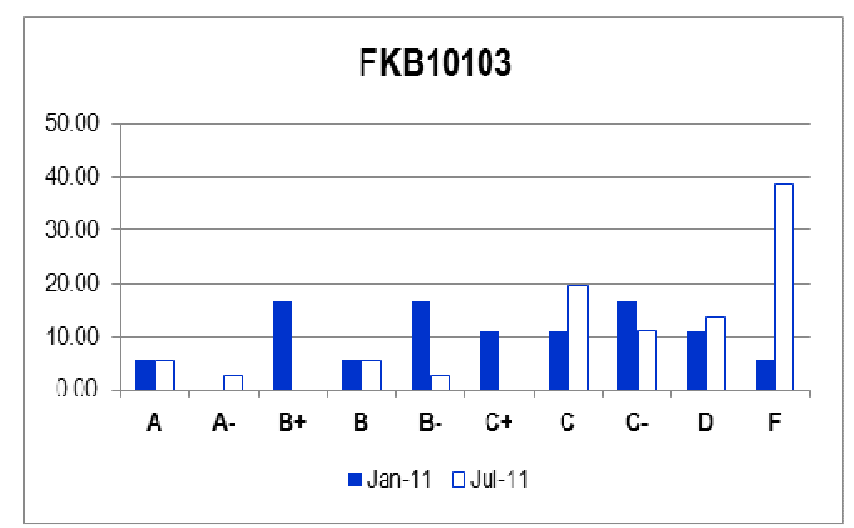

Fig. 2 Students' performance in FKB10103 for semester January 2011 and July 2011 .

Figure 3 shows the students' performance in FKB20203 for January 2011 and July 2011 intakes. The failure rates were $37.50 \%$ and $42.10 \%$ respectively. An increase in the failure rate can be observed. Nevertheless, both rates were quite disturbing for the two intakes. Surprisingly, no students obtained grades between A and C- in the January 2011 intake. The same situation can also be observed in the July 2011 intake as there were no students obtained grades between A- and C+. In general, as compared to FKB10103, the performance of FKB20203 has worsened for the two intakes.

Figure 4 shows the result of FSB33503 of January 2011 and July 2011 intakes. The student's performance in this subject was found to be better than in FKB10103 and
FKB20203. $15.38 \%$ of July 2011 intake and $23.53 \%$ of January 2011 intake scored $\mathrm{B}+$ and above. The rest of the scores, scattered between $\mathrm{B}$ and $\mathrm{C}$ represent $84.62 \%$ and $76.47 \%$ for July 2011 intake and January 2011 intake respectively. No failure can be observed for FSB33503 for these two intakes.

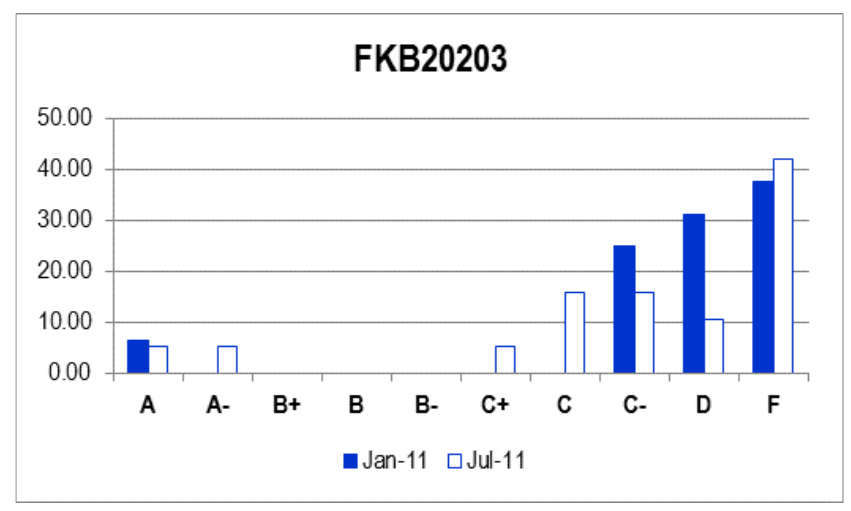

Fig. 3 Students' performance in FKB20203 for semester January 2011 and July 2011.

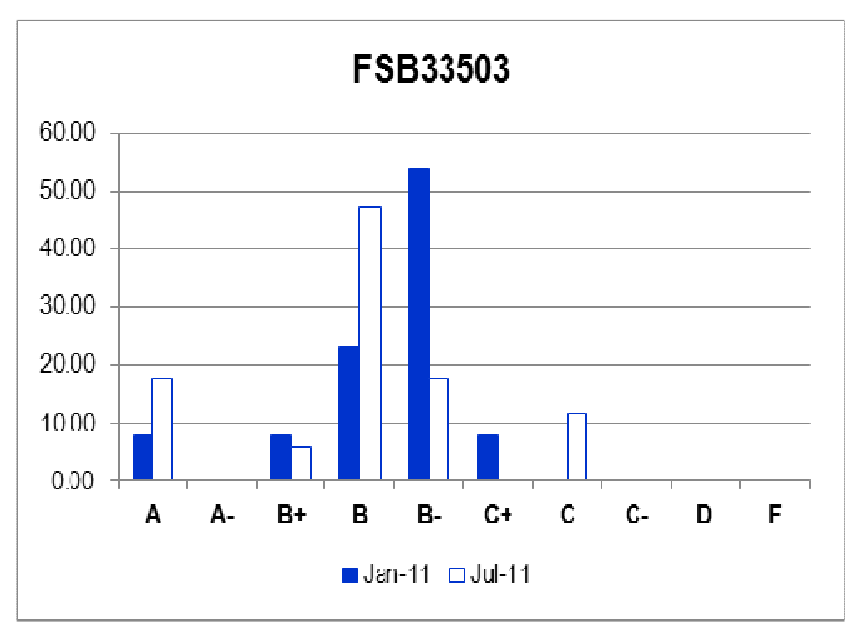

Fig. 4 Students' performance in FSB33503 for semester January 2011 and July 2011.

From these results, the students' performance in mathematics was not as good as image processing. The rate of failure in mathematics seems to increase from one intake to another and also from FKB10103 to FKB20203. If this scenario continues, it will upset the number of students graduating on time. This may also lead to the decline in the performance of technical subjects such as image processing in the future. One of the factors that contribute in the drop of the students' performance in mathematics is the inability to relate the topics learnt in mathematics to the technical subject. Thus, making mathematics non meaningful and difficult to be absorbed. A factor identified to contribute to the drop of the students' performance is the confusion of the terminologies used in this subject. This is due to the diversity of definitions used by both mathematics and image processing lecturers.

\section{B. Common Terminologies with Diverse Definitionsing}

Common definitions for the terminologies used in mathematics and image processing subjects are very 
important. Diversity in definitions has caused students' difficulties in understanding the mathematical application in image processing subject. In this paper, eight commonly used terminologies in both subjects have been identified as shown in Table 1.

TABLE I

THE COMMON TERMINOLOGIES IN MATHEMATICS AND IMAGE PROCESSING

\begin{tabular}{|c|c|c|}
\hline Terminology & Mathematics & Image Processing \\
\hline Origin & $\begin{array}{l}\text { Centre of the coordinate } \\
\text { system represented by } \\
(0,0)\end{array}$ & $\begin{array}{l}\text { Initial location of the } \\
\text { coordinate system } \\
\text { represented by }(0,0)\end{array}$ \\
\hline Axis & $\begin{array}{l}\text { Both } \mathrm{x} \text { and } \mathrm{y} \text { axes } \\
\text { have positive and } \\
\text { negative direction } \\
\mathrm{x} \text {-axis can be } \\
\text { directed to the left or } \\
\text { right of the origin } \\
\text { y-axis can be } \\
\text { directed up or down } \\
\text { from the origin }\end{array}$ & $\begin{array}{l}\text { Both } \mathrm{x} \text { and } \mathrm{y} \text { axes have } \\
\text { positive direction only } \\
\text { - } \mathrm{x} \text {-axis is directed down } \\
\text { from the origin } \\
\text { - } \quad \mathrm{y} \text {-axis is directed to the } \\
\text { right of the origin }\end{array}$ \\
\hline Coordinate & $\begin{array}{l}(\mathrm{x}, \mathrm{y}) \text { is used to locate a } \\
\text { point }\end{array}$ & $\begin{array}{l}\text { - }(\mathrm{x}, \mathrm{y}) \text { is used to locate } \\
\text { the pixel element } \\
\text { also represents the row } \\
\text { and column in the } \\
\text { digital image }\end{array}$ \\
\hline Arc & $\begin{array}{l}\text { A set of points that lie on } \\
\text { a circle and that are } \\
\text { positioned within a } \\
\text { central angle. }\end{array}$ & $\begin{array}{l}\text { A finite set of pixels } \\
\text { representing a portion of a } \\
\text { curve }\end{array}$ \\
\hline Area & $\begin{array}{l}\text { The space contained } \\
\text { within a shape }\end{array}$ & $\begin{array}{l}\text { The number of pixels in a } \\
\text { region }\end{array}$ \\
\hline Border & $\begin{array}{l}\text { Boundary is a border that } \\
\text { encloses a space or an } \\
\text { area }\end{array}$ & $\begin{array}{l}\text { The set of pixels in a } \\
\text { region of a digital image } \\
\text { that is adjacent to pixels in } \\
\text { the region's complement. }\end{array}$ \\
\hline Complement & $\begin{array}{l}\text { The set of all the } \\
\text { elements of a universal } \\
\text { set not included in a } \\
\text { given set }\end{array}$ & $\begin{array}{l}\text { All points in an image that } \\
\text { does not belong to a given } \\
\text { subset of the image. }\end{array}$ \\
\hline Addition & $\begin{array}{l}\text { Finding the total, or sum, } \\
\text { by combining two or } \\
\text { more numbers }\end{array}$ & $\begin{array}{l}\text { A point process that blends } \\
\text { the values of corresponding } \\
\text { pixels in two input images. } \\
\text { A single parameter controls } \\
\text { which input image } \\
\text { dominates the output } \\
\text { image. }\end{array}$ \\
\hline
\end{tabular}

To overcome this problem, a method to link between mathematics and image processing subjects will be developed. This paper focuses on the development of an integrated teaching and learning module of mathematics and image processing subjects known as Maths-IP Room. The purpose of this module is to increase students' understanding in both subjects.

\section{Identification and Mapping of Topics}

The important task before any integration of topics between two subjects is to review and identify the highly related topics between both of them. In this paper, the scope of work was limited to mathematics and image processing subjects which are offered by UniKL MFI. The focus given in this research was to identify and map the related topics in mathematics and image processing. As a beginning, a communication between lecturers from both sections, Mathematics and Industrial Automation was established. Through detail discussions on main topics, sub-topics, terminologies and application examples in mathematics and image processing, it was found that similarities exist in both subjects. Some topics and sub-topics could have been related easily because they usually represent basic calculations in mathematics and at the same time, represent calculation applications in image processing. An example is the topics of Matrix operations in mathematics and image operations in image processing. In our case, the overall comparison and identification of highly related topics and sub-topics in FKB10103, FKB20203 and FSB33503 are shown in Figure 5 . It is interesting to discover that there are about $45 \%$ of FKB10103 topics and 20\% of FKB20203 topics directly contribute to about $90 \%$ of the basic calculations in image processing's topics and sub-topics. Therefore, FSB33503 can be said as highly dependent on mathematics because almost all of its topics are directly related to topics such as Linear Algebra in FKB10103 and Pre-Calculus in FKB20203.

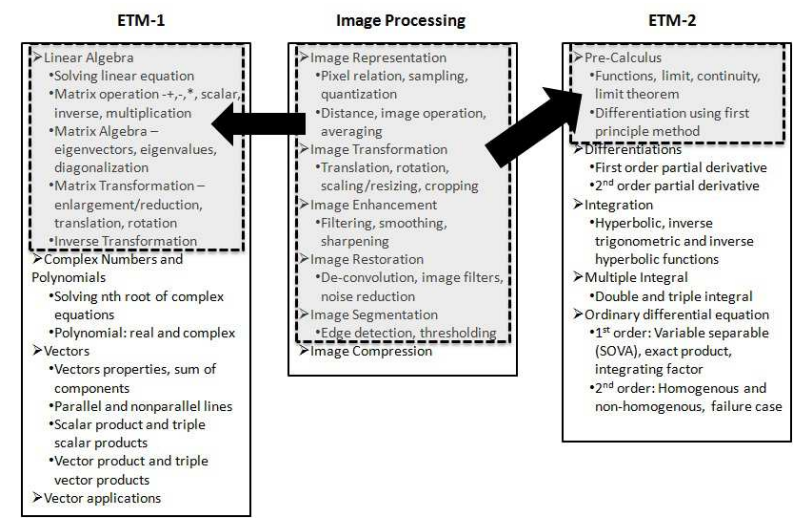

Fig. 5 The topics and sub-topics in FKB10103, FKB20203 and FSB33503 that are identified as having significant relations

\section{Mapping Outcomes}

Literatures have shown that many engineering or technical educators have proposed changes to the way that mathematics is taught to engineering students or technologists. Some of the suggestions are mathematics should be taught by engineering lecturers rather than mathematics lecturers, integrating mathematics and engineering or technical subjects or even a more radical approach is by doing a revamp in engineering or technical curriculum [11]. At the same time, the mathematics community believes that by considering a broader notion of mathematics in developing mathematical thinking will be more advantageous to engineering or technical students [11].

Common needs between these two fields have to be investigated and achieved. Thus, this study aims to propose a new model of teaching mathematics for technical students by integrating the teaching of mathematics and its related counterpart. A teaching method reform will be proposed from teaching mathematics and technical subjects separately to an integrating teaching approach. The main objective of this approach is to find one teaching technique that can cater both, mathematics and technical subject. The collaboration of mathematics and technical subjects are likely to be an effective approach of teaching any mathematics subjects [12]. This integration method will give students a great opportunity to experience a more encouraging environment in learning mathematics concepts. The relevant technical 
activities and examples will help students to think critically about the related mathematical concepts. Furthermore, mathematics should be taught in conditions that lead to its real life applications.

In this study, there are two sub-topics of Linear Algebra involved, namely Matrices and Matrix Transformation. The applications of matrices in technical and engineering fields are very broad, but this study focuses on the application of Matrices and Matrix Transformation in Image Processing. The current teaching practice of Mathematics and Image Processing will be enhanced through the integration of both subjects (Figure 6 and Figure 7). Lecturers from Mathematics Section and Industrial Automation Section will be involved in teaching both subjects where the basic mathematical knowledge will be taught by the mathematics lecturers. The applications of the mathematical knowledge will be explained through the content of Image Processing. This part will be covered by Image Processing lecturers.

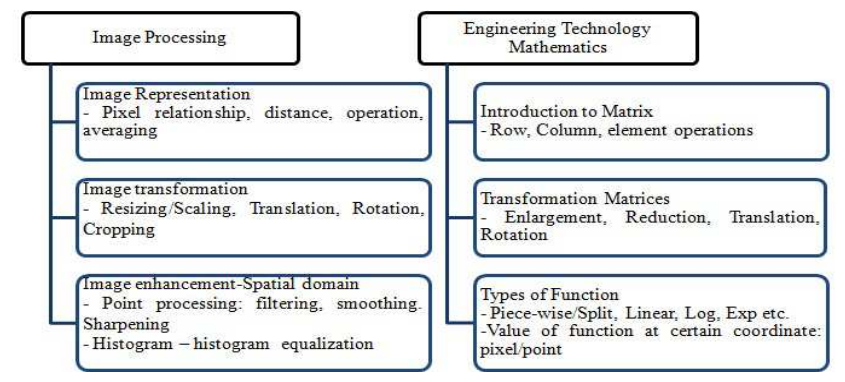

Fig. 6 Identified topics for enhancement in teaching and learning of image processing by integrating mathematics
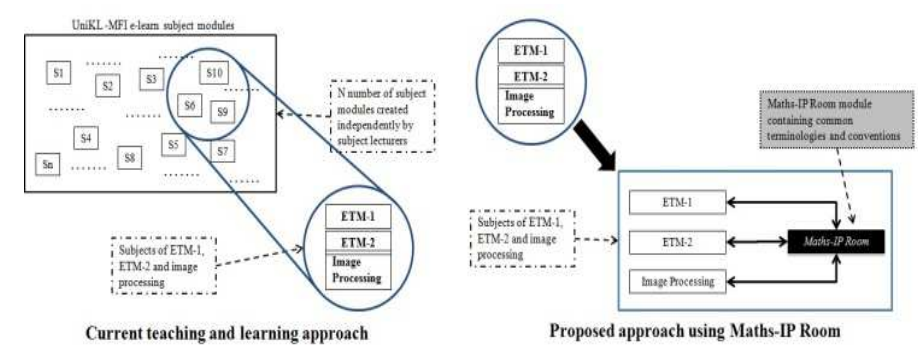

Fig. 7 Identified topics for enhancement in teaching and learning of image processing by integrating mathematics

These two subjects which currently taught separately in different semester will be brought together in a virtual library called the Maths-IP Room through applications and examples. Using the existing e-learn system, developed by our institution, the Maths-IP Room will provide a better learning environment for Bachelor of Engineering Technology in Industrial Automation and Robotics Technology students. In this proposed model, the students will also be able to transfer their mathematical skills into the application of Image Processing.

\section{CONCLUSIONS}

Students will be able to integrate a new concept learnt from the proposed model of teaching, if that concept makes sense to them. This means that lecturers must disseminate the meaning of the concepts to the students. The dissemination process will be meaningful if students understand the link between the concepts learned and their related applications. This study has proposed the integration in the teaching of Mathematics and one of its application subjects that is Image Processing. In this approach, the mathematical operations to the matrices can be applied in manipulating images. In this sense, the teaching of Matrices and Image Representation can be taught simultaneously. It is hoped that the students of Industrial Automation and Robotics Technology can overcome the difficulties faced in learning mathematics and appreciate better the learning of mathematics through the real world application. Thus, a better result of the students' performance in FKB10103 and FKB20203 is hoped to be obtained. Furthermore, the lecturer will also be able to teach the contents of Matrices in more stimulating and motivating environment.

\section{ACKNOWLEDGMENT}

The authors would like to thank Universiti Kuala Lumpur Malaysia France Institute (UniKL MFI) for giving the team a chance to continue with the project.

\section{REFERENCES}

[1] C. M. Caridade, "Applying Image Processing Techniques to motivate students in Linear Algebra Classes," in Proceedings of SEFI Annual Conferences of European Society for Engineering Education, Lisbon.

[2] J. S. a. A. C. Gail Rose, "Connecting Artistically-Inclined K-12 Students to Physics and Math Through Image Processing Examples," in 13th IEEE Digital Signal Processing Workshop \& 5th Signal Processing Education Workshop (DSP/SPE2009), 2009.

[3] T.-S. Weng, "3D Mathematics - Seeing is Believing," International Journal of e-Education, e-Business, e-Management and e-Learning, vol. 1, no. 1, April 2011.

[4] M. V. J. T. a. M. L. Heikki Huttunen, "Motivating The Mathematics Studies by Real-life Examples of Signal Processing and Communications Engineering," in IEEE Digital Signal Processing Workshop and IEEE Signal Processing Education Workshop (DSP/SPE), 2011.

[5] A. S. A.-H. a. R. H. Milne, "The role of mathematics and physics in engineering degrees," in 100 METSMaC-I, CiteSeerX, 2008, pp. 100-106.

[6] D. E. a. M. S. George Bebis, "Review of Computer Vision Education," IEEE Transaction on Education, VOL. 46, NO. 1, FEBRUARY 2003, vol. 46, no. 1, pp. 2-21, 2003.

[7] S. D. R. A. D. M. J. T. S. W. a. M. A. .. Y. G.C. Orsak, "The Infinity Project: Expanding Signal Processing Education To The High School Classroom," in IEEE Workshop on the Applications of Signal Processing to Audio and Acoustics, 2001.

[8] A. MacAndrew, "Teaching Image Processing Using Minimal Mathematics," in Proceedings of the 5th Australasian Conference on Computing Education (ACE), Adelaide, 2003.

[9] W. A. S. a. D. J. Hamilton, "Pedagogical Issues for Effective Teaching of Biosignal Processing and Analysis," in 32nd Annual International Conference of the IEEE Engineering in Medicine and Biology Society, Beunos Aires, 2010.

[10] T. P. Summey, S. Valenti, "But we don't have an instructional designer: Designing online library instruction using ISD techniques," Journal of Library \& Information Services in Distance Learning, vol. 2, no. 1-2, pp. 169-182., 2013.

[11] M. Cardella, "Which mathematics should we teach engineering students? An empirically grounded case for a broad notion of mathematical thinking," Teaching Mathematics and its Applications, vol. 27, no. 3, pp. 150-159., 2008.

[12] M. Allali, "Linear algebra and image processing," International Journal of Mathematical Education in Science and Technology, vol. 41, no. 6, p. 725-741, 2010. 